\title{
BUCHANZEIGEN
}

WIENER SLAVISTISCHES JAHRBUCH, Band 55/2009, 305-311

(C) 2009 by Österreichische Akademie der Wissenschaften, Wien

Sigrun Bielfeldt, Selbst oder Natur. Schellings Anfang in Rußland (= Arbeiten und Texte zur Slavistik, Band 83), München (Verlag Otto Sagner) 2008, 459 S.

Die in Richtung Aufklärung hin orientierten bildungspolitischen Instanzen im Russland von Zar Alexander I. hatten es sich bestimmt anders vorgestellt. Sie schickten nämlich den lekar' Daniil Michajlovič Vellanskij (1774-1847) an deutsche Universitäten, damit aus ihm ein allseits ausgebildeter Arzt würde, doch die Begegnung mit Friedrich Wilhelm Joseph von Schelling in Jena und Würzburg und mit der entsprechenden Phase seiner Lehre verlieh Vellanskijs weiterer Laufbahn eine andere, und zwar philosophische Richtung. Tatsächlich kristallisierte sich die neue Tendenz in der Forschung, die Vellanskij nach der Auseinandersetzung mit Schelling einschlug, in seiner 1805 in Petersburg veröffentlichten Proljuzija k medicine kak osnovatel'noj nauke heraus, deren Zweck nach Vorhaben ihres Autors eigentlich eine Erläuterung seiner auf Latein geschriebenen Dissertation De reformatione theoriae medicae, auspicio novae Philosophiae naturalis incepta (1807) war.

Von der Person und dem Schaffen Vellanskijs, dem vermutlich allerersten russischen Hörer Schellings, ausgehend, entfaltet Sigrun Bielfeldt in Selbst oder Natur. Schellings Anfang in Rußland (ihrer Tübinger Habilitationsschrift aus dem Jahre 2000), eine umfangreiche und spannende Analyse der Rezeption des Transzendentalen Idealismus Schellings in Russland. Die Bezeichnung ,spannend“ ist dabei durchaus gerechtfertigt: Bielfeldt vermag nämlich durch ihre Arbeit nicht nur die Debatte um die Nachfolge Kants, die einen neuen Höhepunkt der klassischen deutschen Philosophie einleitete, „,von außen“, d. h. durch die russische Rezeption des kantischen Kritizismus und ihre Reaktion darauf, besonders wirksam zu beleuchten, sondern sie bringt sogar kulturgeschichtlich-weltanschauliche Konstanten ans Licht, die man als kennzeichnend für das russische Denken betrachten kann.

Sowohl Vellanskij als auch andere Vertreter der russischen Intelligenz vom Rang z. B. eines Karamzin fassen die theoretische Philosophie Kants als einen eher misslungenen Versuch der Begründung der wissenschaftlichen Erkenntnis auf. Sie sei nämlich eine ,negative“ Philosophie, die den Realgrund von Rationalität nicht genug thematisiert habe. Erfolgreicher war bei den Russen dagegen wohl Kants praktische Philosophie, weil in seiner Moralphilosophie das, was kein Gegenstand menschlicher Erkenntnis sein darf, doch eine Art ontologischen Status wiedererlangt. Es ist kein Zufall, dass jene Stränge des schellingschen Denkens, die in Russland am meisten Gefallen fanden, seine Würzburger Identitätsphilosophie und die späte Offenbarungsphilosophie sind (Bielfeldt betont auch zu Recht, wie problematisch eine eindeutige chronologische Einstufung der Philosophie dieses Autors ist, deren Phasen nicht selten in Widerspruch zueinander stehen). Schellings Identitätsphilosophie ist nämlich eine Huldigung an die Natur; seine evolutionistisch angehauchte Naturphilosophie steht übrigens in brisantem Widerspruch zum Begriff des Absoluten, das als Einheit von Nicht-Ich und Ich durchaus Gott gleichzusetzen ist - Deus sive natura, wie die in diesem Zusammenhang funda- 
mentale Philosophie Spinozas behauptet. In der Identitätsphilosophie findet nämlich keine Gegenüberstellung zwischen dem erkennenden Ich und dem zu erkennenden Nicht-Ich, sondern die unmittelbare Identität von Dasein und Denken statt (als Beweis dafür bringt Vellanskij das prägnante Bild der pylinka, d. h. des Staubkorns, das seiner Auffassung nach die Übereinstimmung zwischen diesen beiden Instanzen eindeutig bezeugt). Im Gegensatz zum Kantismus erlangt das Ich bei Schelling und vielleicht noch eindeutiger bei Vellanskijs Rezeption des Schellingschen Würzburger Systems ontologische Würde erst nach der Selbstaufhebung des „Ego“; sie allein ermöglicht es ihm, aus der Dimension der All-Einheit zu schöpfen. Dabei verweist Bielfeldt auf die ausgesprochen ähnlichen Auffassungen, die für die Slavophilen und die gesamte philosophische Schule, die von Vladimir Solov'ev ausging, typisch sind, wobei den Westlern die typisch kantisch-rationalistisch, abstrahierende und zugleich isolierende Tätigkeit des Verstandes zugeschrieben (und vorgeworfen) wurde.

Die umfangreiche Auseinandersetzung mit der Natur und somit mit dem Realen schlechthin (aufgrund derer die Einstellung der russischen Intellektuellen zu Schellings Philosophie wohl um Einiges positiver als dem kantischen Kritizismus gegenüber gehalten war) lässt es weniger verwunderlich erscheinen, dass sich auch sowjetische Autoren Studien zu Schelling widmeten. Dennoch kann man ein gewisses Staunen nicht unterdrücken, wenn man bedenkt, dass im Jahre 1936, als u. a. die furchtbare Ära der stalinistischen Schauprozesse eingeleitet wurde, eine russische Übersetzung von Schellings System des transzendentalen Idealismus herauskam.

Die Proljuzija Vellanskijs befindet sich im Buch von Bielfeldt als Anhang, und zwar in deutscher Sprache unter Angabe der entsprechenden relevanten philosophischen Termini aus dem russischen Original. Ein Kommentar der Verfasserin sorgt zusätzlich für die Deutlichkeit dieses Textes.

Es handelt sich also beim Band von Bielfeldt um ein Buch, das für Slavisten genauso wie für Philosophen, Philologen und Komparatisten von großem Interesse sein wird, geht es in der vorliegenden Studie doch um eine etwaige "Wahlverwandtschaft" zwischen deutschem, Schellingschem Idealismus und russischer Kultur. Insgesamt lässt der Band keine Wünsche offen - außer dem, dass in einer etwaigen künftigen Auflage jene Tippfehler ausgebessert werden, die in der ersten Auflage vorkommen.

\section{Alberto Gerosa}

Institut für Slawistik der Universität Wien

Universitätscampus $\mathrm{AAKH}_{2}$, Hof 3

Spitalgasse 2, 1090 Wien, Österreich

alberto.gerosa@univie.ac.at

Andriej Moskwin, Stanisław Przybyszewski w kulturze rosyjskiej końca XIX - początku XX wieku, Warszawa (Wydawnictwo Uniwersytetu Warszawskiego) 2007, $251 \mathrm{~S}$.

Utwory Przybyszewskiego ukazywały się w Rosji w zasadzie natychmiast po ich wydaniu w Niemczech i w Polsce i można śmiało stwierdzić, że ten polski autor stanowił nieodłączną część rosyjskiej kultury przedrewolucyjnej Rosji. Szczyt popularności pisarza przypadł tam na lata 1908-1911. W tym okresie w języku rosyjskim ukazały się 52 książki autora. Po tym czasie autor dość długo popadł w zapomnienie, po którym jednak Stanisław Przybyszewski znowu powrócił do rosyjskiego czytelnika. 
W swojej książce Andriej Moskwin podejmuje próbę wyczerpującego opracowania tematu recepcji twórczości Stanisława Przybyszewskiego w Rosji. Już sam fakt wskazania na konieczność badań nad recepcją pisarzy polskich w Rosji wydaje się mieć tutaj ogromne znaczenie. Moskwin przypomina dotychczasowe badania nad recepcją twórczości Przybyszewskiego w Rosji, wskazując jednocześnie ich braki i niedostatki. Sam podejmuje pracę nad uzupełnieniem dotychczasowych niedociągnięć, przeprowadza wyczerpujące studia nad oddziaływaniem twórczości Przybyszewskiego na życie kulturalne Rosji, jak i podaje wnikliwy obraz następujących po sobie faz recepcji dzieł autora, wskazując na zmienny w czasie odbiór dzieł Przybyszewskiego przez rosyjskiego czytelnika.

W dziewięciu rozdziałach poprzedzonych wstępem autor monografii ukazuje związki Przybyszewskiego z kulturą i literaturą Rosji. Porusza takie problemy, jak: Przybyszewski a rosyjski symbolizm, związki i paralele między twórczością prozatorską Przybyszewskiego a rosyjską powieścią popularną, czy też powiązania dramatu Przybyszewskiego z rosyjskim dramatem naturalistyczno-symbolicznym. Moskwin nie pomija też wpływów Przybyszewskiego na teatr rosyjski początku XX wieku, i przedstawia dzieło Przybyszewskiego w rosyjskiej kinematografii. Interesujący jest rozdział dotyczący oceny twórczości polskiego autora przez rosyjską cenzurę, z którego dowiadujemy się m.in., że Requiem aeternam zostało przez cenzurę całkowicie zakazane, a Homo sapiens dopuszczone zostało co prawda do czytelnika, ale w wersji dość okrojonej. Z utworów dramatycznych, które w sumie dość łatwo przechodziły przez cenzurę, zakazany został druk epilogu dramatycznego Goście.

Godnym szczególnego podkreślenia i podnoszącym dodatkowo badawczą wartość publikacji jest fakt, że podczas pracy nad monografią Moskwin dotarł do niepublikowanych wcześniej materiałów archiwalnych oraz wielu tytułów prasowych z przełomu XIX i XX wieku, niedostępnych w Polsce. Jak sam pisze, w swoich badaniach opierał się głównie na badaniach dokumentów źródłowych, uzyskanych w rosyjskich archiwach i większość odnalezionych przez niego i wykorzystanych w monografii dokumentów nigdy jeszcze nie była publikowana.

Wykorzystując te archiwalne materiały, jak i zestawiając utwory z dorobku Przybyszewskiego z utworami m.in. Dostojewskiego Moskwinowi udaje się rzetelnie i wyczerpująco przedstawić sposób odczytywania i interpretacji dzieła polskiego autora w Rosji.

Jolanta Krzysztoforska-Doschek

Institut für Slawistik der Universität Wien

Universitätscampus $\mathrm{AAKH}_{2}$, Hof 3

Spitalgasse 2, 1090 Wien, Österreich

jolanta.doschek@univie.ac.at

Rękopisy cerkiewnosłowiańskie w Polsce. Katalog, wydanie drugie zmienione, opracowali Aleksander Naumow oraz Andrzej Kaszlej, przy współpracy Ewy Naumow i Jana Stradomskiego, Kraków (Wydawnictwo scriptum) 2004, XIV + 569 S.

Wie in der Einleitung dieses umfangreichen und ansprechend gestalteten Katalogs festgestellt wird, bilden die kyrillischschriftlichen Sammlungen in Polen (ihnen stehen nur zwei kleine glagolitische Handschriftenfragmente gegenüber) mit jenen in den Nachbarländern eine Einheit. Die wichtigste Grundlage der polnischen Bestände bilden die Sammlungen aus dem Gebiet Polens selbst, vor allem jene, die aus dem griechisch-katholischen Domkapitel zu Przemyśl stammen und im Jahr 1946 im Zuge der „Weichselaktion“ nach Warschau transferiert wurden. Hinzu treten Bestände aus dem Balkanraum, aus Moskau sowie aus Polack, 
einige Handschriften aus Moldawien sowie in Polen aufbewahrte Besitztümer der ehemaligen Staatsbibliothek Berlin. Gewürdigt wird im Vorwort insbesondere die Bedeutung des griechisch-katholischen Bischofs von Przemyśl Ivan Snihurs'kyj sowie der im Przemyśler Domkapitel beschäftigten Geistlichen Ivan Lavrivs'kyj und Volodymyr Podolyns'kyj, die im 19. Jahrhundert Grundlegendes im Bereich der Sammlung und Erfassung der kirchenslavischen Handschriften in Przemyśl leisteten. Als ein Spezifikum der in den Beständen deutlich überwiegenden Handschriften aus Polen-Litauen insgesamt bezeichnet Aleksander Naumow, der Autor der Einleitung, ,wierność rodzimej kijowsko-halickiej tradycji, silna i świadoma więź z Bałkanami i Górą Athos, literackie i teologiczne osiągnięcia XVI- i XVII-wiecznych obrońców prawosławia oraz cerkiewnosłowiańska twórczość unitów“ (S. VIII). Das Prunkstück der kyrillischen Handschriften in Polen aber bildet der aus Bulgarien stammende Codex Suprasliensis, der im Katalog als Position 633 erfasst wird.

Die 1.064 Positionen des Katalogs werden alphabetisch angeordnet, von Akatystarz bis Żywot. Die übersichtlich gestalteten Einträge (S. 1-499) enthalten Angaben zu „Typ księgi“, „Rodzaj księgi“, fallweise „Nazwa zwyczajowa“, „Miasto“ oder „Miejscowość““ (Aufbewahrungsort), „Biblioteka“, „Sygnatura aktualna“, „Datacja“, „Ilość kart“”, „Wymiary“, fallweise „Oprawa“, fallweise „Stan zachowania“, „Treśćc, fallweise „Sygnatura stara“, fallweise „Zapisy“, „Historia rękopisu“ und „Bibliografia“. Auf den Seiten 501-520 folgt eine allgemeine Bibliographie, hieran schließt sich ein Index der kirchenslavischen Werke, wobei zutreffend festgestellt wird, dass ,określenie języka jako cerkiewnosłowiański też jest w znacznym stopniu umowne“ (S. 501). Im Personenverzeichnis (S. 531-547) werden sämtliche Personen außer den nur in der Bibliographie erfassten, sowohl Autoren als auch Konsulenten u. a., angeführt. Der Index der Herkunftsorte verstärkt den Eindruck vom Reichtum und von der Vielfalt der kirchenslavischen Bestände an den polnischen Bibliotheken zusätzlich. Am Schluss des Bandes finden sich eine Konkordanz der Signaturen und Katalogbeschreibungen sowie ein übersichtliches Inhaltsverzeichnis.

Für ihre überaus umsichtige und sorgfältige Arbeit ist dem Bibliothekar Andrzej Kaszlej, dem Philologen Aleksander Naumow und allen, die zum Gelingen des ausgesprochen benützerfreundlichen Katalogs beigetragen haben, mit Nachdruck zu danken.

Michael Moser

Institut für Slawistik der Universität Wien

Universitätscampus AAKH, Hof 3

Spitalgasse 2, 1090 Wien, Österreich

michael.moser@univie.ac.at

Das Lemberger Irmologion. Die älteste liturgische Musikhandschrift mit Fünfliniennotation aus dem Ende des 16. Jahrhunderts; herausgegeben und eingeleitet von Jurij Jasinovs'kyj; übertragen und kommentiert von Carolina Lutzka (= Bausteine zur Slavischen Philologie und Kulturgeschichte. Neue Folge, Reihe B: Editionen, Band 24), Köln - Weimar - Wien (Böhlau) 2008, LVI + 509 S.

Das anzuzeigende Buch ist - neben der in Lemberg erscheinenden Reihe Kalophonia eine weitere Frucht der Lemberg-Würzburger Kooperation im Bereich der slavisch-byzantinischen Hymnographie. Zusätzlich zum Herausgeber Jurij Jasinovs'kyj, seines Zeichens Professor für Musikwissenschaft und Kulturgeschichte des Spätmittelalters und der frühen Neuzeit an der Katholischen Universität Lemberg, und der Editorin Carolina Lutzka, Mitarbeiterin am 
Institut für Slavistik sowie am Ostkirchlichen Institut der Universität Würzburg, wirkte an ihm auch der - nicht nur - durch seine unlängst erschienene monumentale Edition (Christian Hannick, Das altslavische Hirmologion, Freiburg i. Br. 2006 [= Monumenta linguae slavicae L]) einschlägig ausgewiesene Kenner des slavischen Irmologion und Würzburger Ordinarius für Slavistik Christian Hannick mit. Seiner Feder entstammt das Vorwort (S. IX-XI), das auch in ukrainischer Übersetzung vorliegt (S. XIII-XV). Die sowohl auf deutsch- als auch auf ukrainischsprachige Benutzer abzielende zweisprachige Konzeption des Bandes wird auch in der Einleitung und dem Incipitarium von Jurij Jasinovs'kyj beibehalten (ukrainisch S. XVIIXXXII, deutsch S. XXXIII-XLIX), nicht aber in Cornelia Lutzkas „Bemerkungen zur Edition" (S. LIII-LIV) und ihrem die Edition (S. 1-505) in Fußnoten begleitenden Kommentar.

Das hier der wissenschaftlichen Öffentlichkeit zugänglich gemachte Irmologion, „ein Gesangbuch, das Gesänge unterschiedlicher Hymnengattungen aus verschiedenen liturgischen Büchern des byzantinischen Ritus in sich vereinigt" (S. XXXIII), ist der früheste bekannte Vertreter der ukrainisch-ruthenischen Irmologientradition. Diese zeichnet sich dadurch aus, dass sie nicht, wie die älteren Denkmäler der Rus', mittels Neumen notiert ist, sondern die so genannte Kiever Quadratnotation zeigt, ,die die ukrainische Version der westeuropäischen Liniennotenschrift darstellt" (S. XXXV); im Vergleich zur Neumennotation ist die Kiever Quadratnotation leichter erlernbar und übersichtlicher.

Gut erkennbar ist diese modernere musikalische Notation im Editionsteil, der neben der diplomatischen Textwiedergabe ein vollständiges Faksimile der Handschrift zeigt. Bedauerlicherweise wurden jedoch die Noten nicht ediert, obwohl deren Edition auch dem nicht musikologisch vorgebildeten Philologen die Möglichkeit eines vertieften Eindringens in die Materie ermöglicht hätte. Ein Grund für die editorische Nichtberücksichtigung der Noten mag ein darstellungstechnischer gewesen sein: In der notenlosen Editionsform gelingt es, die Texte jeweils direkt unterhalb der entsprechenden Faksimile-Seiten abzudrucken, was außerordentlich benutzerfreundlich ist.

Die Edition der kirchenslavischen Texte, die sprachlich immer wieder von der wenige Jahrzehnte nach der Entstehung der Handschrift durch Meletij Smotryc'kyj kodifizierten Norm abweichen - man denke nur an die Schreibweise светаго (z. B. S. 455) -, zeugt von großer Sorgfalt. Verwunderlich ist nur, dass zwar im Incipitarium die supralinearen Grapheme als solche realisiert sind, nicht aber in der Edition, in welcher diese kommentarlos in die Zeile eingerückt werden. Dies erweckt auf den ersten Blick den Eindruck vergessener Jer-Grapheme am Wortende.

Besonders hervorzuheben ist der von Carolina Lutzka erstellte konzise Kommentar zu den einzelnen Texten, der über ihren Verwendungszweck und die griechischen Vorlagen Auskunft gibt und auf die einschlägigen publizierten Primärquellen verweist.

Der vorliegende Band ist nicht nur aus philo- und hymnologischer Perspektive relevant; er verdeutlicht einmal mehr die faszinierende Mittlerstellung der ukrainisch-ruthenischen Gebiete zwischen lateinisch-westlicher und byzantinisch-östlicher Kultur. Diese manifestiert sich, neben der Verbindung ostkirchlicher liturgischer Texte mit westlicher musikalischer Notation, im Vagieren zwischen Sprachen - zusätzlich zum Kirchenslavischen erscheinen einzelne ukrainisch-ruthenische, griechische, lateinische und polnische Worte und Phrasen - und Alphabeten - kyrillisch, griechisch und lateinisch. Es bleibt zu hoffen, dass vom hier präsentierten Material in weiterführenden Forschungen Gebrauch gemacht wird.

\section{Achim Rabus}

Slavisches Seminar der Universität Freiburg

Werthmannstraße 14

79085 Freiburg i. Br., Deutschland

achim.rabus@slavistik.uni-freiburg.de 
Juraj Furdík, Teória motivácie v lexikálnej zásobe. Editor: Martin Ološtiak, Košice (Vydavatel'stvo LG) 2008, $95 \mathrm{~S}$.

Dieses Buch hätte auch Cours de motivatologie générale heißen können: Es wurde von seinem Herausgeber aus Aufnahmen von Vorlesungen des Autors sowie aus Anmerkungen seiner Studenten zusammengestellt (darüber informiert uns der Herausgeber im Vorwort auf S. 5-9 und in seiner wertvollen zusammenfassenden Einleitung Motivatológ Juraj Furdik, S. 11-23). Und wie bei de Saussures „Cours“ ist eine solche Form der Entstehung auch im Falle dieser posthumen Publikation von Furdík keineswegs zum Schaden der Sache; ganz im Gegenteil eröffnet der schmale Band eine Reihe von weiterführenden Gedanken.

Unter Motivation versteht Furdík im Grunde die Formen der Eingliederung von lexikalischen Einheiten ins Sprachsystem, und er bemüht sich um eine komplexe klassifizierende Beschreibung dieser Formen. Er unterteilt dabei in der Folge die lexikalische Motivation in mehrere Typen. Die erste Unterteilung ist jene in die grundlegenden Motivationen (die den ganzen Wortschatz betreffen), die Überbaumotivationen (die nur Teile des Wortschatzes betreffen) und die Kontaktmotivationen. Im Rahmen der grundlegenden Typen unterscheidet Furdík zwischen der elementaren oder paradigmatischen Motivation auf der einen Seite (Beziehungen der Synonymie, Antonymie, Homonymie usw.) und den spezifizierten Motivationen auf der anderen Seite; zu den letzteren zählen die phonologische, semantische, morphologische, wortbildende, syntaktische, phraseologische und onymische Motivation. Die Überbautypen der Motivation sind die expressive, stratifikationelle, terminologische, soziolektale, temporale, territoriale und individualisierende Motivation. Schließlich sind die Kontaktmotivationen einerseits die Akzeptanzmotivation (die die Entlehnungen betrifft), andererseits die Abbreviationsmotivation (als eines der Ergebnisse des Kontakts der gesprochenen Sprache mit ihrer graphischen Form). $\mathrm{Zu}$ diesem Grundteil des Buchs gesellen sich ferner drei fragmentarische, aber nichtsdestoweniger interessante Nachträge über die Dynamik der einzelnen Typen der lexikalischen Motivation, über den Status der Überbaumotivationen und über die Gliederung der Lexikologie nach den einzelnen Typen der lexikalischen Motivation.

Diese kurze Nachricht kann Furdíks bemerkenswertes Buch nicht in seinem ganzen Umfang analysieren, obwohl die Themen, die es eröffnet und über die man lange Abhandlungen schreiben könnte, zahlreich sind (eines der ersten unter diesen wäre sicherlich die Frage, inwieweit die einzelnen Formen der Motivation je nachdem zur Geltung kommen, welcher Sprachtyp in den einzelnen Sprachen dominiert und in welcher Sprachsituation sich die betreffende Sprachgemeinschaft befindet). An dieser Stelle sei vor allem dem Herausgeber für seine mühsame Arbeit gedankt, und die Teória motivácie allen, die sich näher für Lexikologie interessieren, wärmstens und nachdrücklich empfohlen.

Bohumil Vykypěl

Ústav pro jazyk český AV ČR

Veveř́ 97, 60200 Brno, Tschechien

vykypel@iach.cz 
Martin Ološtiak, Jazykovoštruktúrny a komunikačno-pragmatický status vlastného mena (Adaptácia anglických proprií v slovenčine) (= Acta Facultatis philosophicae Universitatis Prešoviensis, Monographia 78), Prešov (Filozofická fakulta Prešovskej univerzity v Prešove) 2007, 225 S. Martin Ološtiak, Lucia Gianitsová-Ološtiaková, Deklinácia prevzatých substantív v slovenčine (= Acta Facultatis philosophicae Universitatis Prešoviensis, Monographia 81), Prešov (Filozofická fakulta Prešovskej univerzity v Prešove) 2007, 152 S.

Die sprachwissenschaftliche slowakistische Produktion an der Universität Prešov setzt in Mannigfaltigkeit und Qualität ihre Tradition fort, die durch solche namhaften Forscher wie Juraj Furdík oder Ján Sabol begründet wurde. Zwei Bücher, auf die wir hier aufmerksam machen möchten, sind besonders aktuell: Sie erfassen und beschreiben methodenbewusst den Prozess der Adaptierung von Fremdwörtern im heutigen Slowakisch.

Das erste Buch, ursprünglich die Doktorarbeit des Autors, hat die Adaptierung der englischen Eigennamen im Slowakischen zum Thema und analysiert diese in ihrer ganzen Breite auf der phonologischen, morphologischen und wortbildnerischen Ebene sowie hinsichtlich der unterschiedlichen Stufen der Akzeptanz von konkreten Formen der Adaptation einzelner Wörter. Das zweite Buch behandelt die morphologische Adaptation der entlehnten Substantive im heutigen Slowakisch.

Beide Bücher sind dem interessierten Leser mit Nachdruck zu empfehlen: Sie sind theoretisch sehr gut fundiert, bringen viel wertvolles sprachliches Material, tragen zum Verständnis eines dynamischen und komplexen sprachlichen Prozesses bei und sind in Fragen der Sprachkultur auch von praktischer Relevanz. Es wäre erfreulich, wenn es ähnlich ausführliche und allseitige Analysen auch für das Tschechische gäbe.

Bohumil Vykypěl

Ústav pro jazyk český AV ČR

Veveří 97, 60200 Brno, Tschechien

vykypel@iach.cz 
